\title{
Haplosporidian parasite in Diporeia spp. amphipods from the Great Lakes region, USA
}

\author{
Gretchen A. Messick
}

NOAA, National Ocean Service, Cooperative Oxford Lab, 904 S. Morris Street, Oxford, Maryland 21654, USA

\begin{abstract}
Light microscope observations of a haplosporidian in Diporeia spp. amphipods from Lakes Michigan and Huron, USA, found that the parasite spore is operculate and measures $8.1 \mu \mathrm{m}$ in length and $6.1 \mu \mathrm{m}$ in width. Round to amorphous sporocysts averaging $23.6 \mu \mathrm{m}$ were present throughout hemal sinuses of infected amphipods. The number of developing spores within a sporocyst was highly variable and spores were observed in various stages of development. Electron microscopy revealed a lid over the operculum of developing spores and documented spores with fairly large and extensive ornamentation. This is the first haplosporidian reported in Diporeia spp. amphipods and only the second haplosporidian from freshwater species.
\end{abstract}

KEY WORDS: Parasite · Haplosporidian · Amphipod · Diporeia spp. · Great Lakes · Microscopy

\section{INTRODUCTION}

Only 2 haplosporidians have been described in freshwater species: Haplosporidium pickfordi (Barrow 1961) in 3 species of freshwater snails, Lymnaea emarginata, Physa parkeri, and Heliosoma campanulata, from the Douglas Lakes region of northern Michigan (Barrow 1961, 1965, Burreson 2001); and Haplosporidium gammari (Ryckeghem 1930) in the freshwater amphipod Rivulogammarus pulex from Leuven, Belgium. Since the haplosporidian in R. pulex does not have an orifice, Larsson (1987) placed it in a new genus Claustrosporidium and new family Claustrosporidiidae after observing it in R. pulex in Sweden. Due to its lack of an orifice in the spore, however, C. gammari has not been accepted as a member of the Haplosporidia (Perkins 1991, 2000).

This report describes the morphology of a recently reported haplosporidian found in $0.7 \%$ of Diporeia spp. amphipods collected from Lakes Michigan and Huron, USA (Messick et al. 2004). Presumed developmental stages and morphology including lid and spore ornamentation was observed using either transmission electron microscopy (TEM) or light microscopy.

\section{MATERIALS AND METHODS}

Amphipods were collected from Lakes Michigan and Huron (Fig. 1) for a survey of parasites and potential pathogens (Messick et al. 2004). Specimens were taken from archived samples from 1986 to 1999 that had been preserved in buffered formalin or were collected in 2000 and preserved in Bouin's fluid (Howard \& Smith 1983, Howard et al. 2004). Preserved amphipods were paraffin-embedded, longitudinally sectioned at 4 to $5 \mu \mathrm{m}$ thickness, and stained with Mayer's hematoxylin and eosin (H\&E) (Luna 1968). Amphipods with haplosporidian infections were additionally stained with Heidenhain's H \& E (Conn et al. 1962) and acid-fast bacteria (AFB) stain (Luna 1968) to elucidate morphological features of the parasite. Prepared slides were observed with a light microscope. A few amphipods infected with what appeared to be a more mature stage of haplosporidian development were deparaffinized, post-fixed and processed for TEM.

\section{RESULTS}

Infected amphipods were found at 9 sites within Lake Michigan and 1 site in Lake Huron (Fig. 1). Infected individuals were found at relatively shallow depths, ranging from 46 to $80 \mathrm{~m}$. The haplosporidian parasite had round to amorphous sporocysts averaging $24 \mu \mathrm{m}$ (SE = 1.04) in length and ranging from 15 to $43 \mu \mathrm{m}(\mathrm{n}=39)$ and were present throughout hemal sinuses of 12 of $1714(0.70 \%)$ amphipods (Fig. 2a). The number of developing spores within sporocysts varied widely, ranging from 6 to $50(n=25)$. Various stages of 


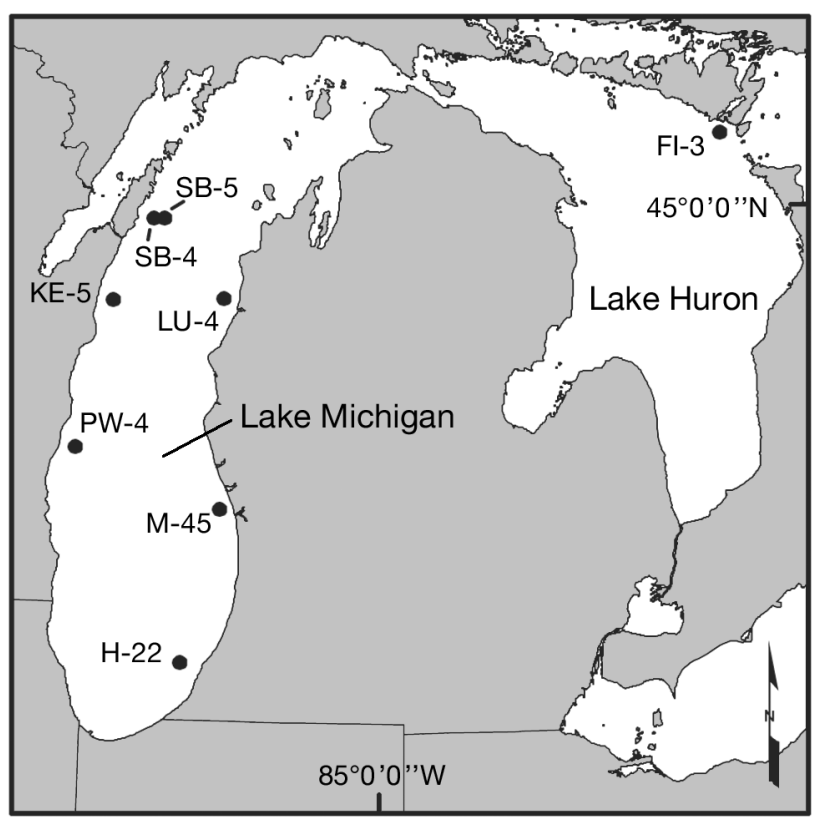

Fig. 1. Sampling sites in Lakes Michigan and Huron where Diporeia spp. amphipods were found with a haplosporidian infection

schizogony and maturation of spores were observed throughout the hemal sinuses of the host. Individual spores measured $8.1 \mu \mathrm{m}$ in length $(\mathrm{SE}=0.23)$ and $6.1 \mu \mathrm{m}$ in width ( $\mathrm{SE}=0.16, \mathrm{n}=21$ ). A hinged operculum was evident on individual, mature spores. A small projection was apparent on the posterior or abopercular end of several mature spores and thin filaments or extensions appeared to be present on a few mature spores.

In what was presumed to be early stages of parasite development, sporonts contained numerous nuclei with small, dense endosomes (nucleoli). Parasite cytoplasm was granular and somewhat basophilic, and there was no obvious separation between nuclei in some early stage sporonts. It appears that sporoblasts developed with larger nuclei, some with acentric endosomes adjacent to the nuclear wall. Occasionally, small sporoblasts were seen individually or as sporonts with single nuclei (Fig. 2b). Sporonts were amorphous, oval or rounded in shape. Sporonts with developing sporoblasts had clear, semi-granular or granular cytoplasm.

In sporoblasts that appeared more mature, the endosporoplasm was defined, dense and basophilic. In some, a translucent area was present between the endosporoplasm and spore wall (Fig. 2c). The endosporoplasm of some sporoblasts contained a secondary basophilic body. Some sporoblasts were ellipsoidal with a limiting membrane apparent and some had dense basophilic structures in the apex of the elliptical developing spore (Fig. 2d). Sporoblasts differentiated and matured into spores; a few maturing spores had what appeared to be a sculptured cell wall with a developing operculum.

Some AFB-stained sporocysts had numerous round sporoblasts with knob-like projections; others had a prominent bar-shaped structure that extended $1.3 \mu \mathrm{m}$ ( $\mathrm{SE}=0.10, \mathrm{n}=21$ ) beyond the sporoplasm (Fig. 2e). The endosporoplasm of some younger spores (those that took up more AFB staining) appeared to be separating, whereas more mature spores (less staining) had a smaller AFB-positive body and faint internal structures or debris; mature spores were resistant to stain (Fig. 2e) (Farley 1965, Taylor 1966).

Mature individual spores, released from sporocysts, had a hinged operculum and a small projection on the abopercular end of the spore (Fig. 2e). A few mature spores had what appeared to be thin, thread-like extensions or filaments emanating from the spore wall on the abopercular end of the spore; some filaments appeared paired and some appeared to be arising from the knob-like structures at the posterior end (Fig. 2f).

TEM was not very useful due to anticipated poor initial fixation. No structures of the sporoplasm in the spore could be elucidated, but TEM did show a lid over the operculum of developing spores and documented that spores likely have fairly large and extensive ornamentation (Fig. 2g). The diameter and length of the filaments observed with TEM are reminiscent of Haplosporidium pickfordi, but scanning electron microscopy (SEM) is required to corroborate.

Specimens for the present study were obtained from formalin-fixed archived samples that are not adequately preserved for additional SEM investigation to further explore the morphology of the parasite or to conduct molecular analysis. Obtaining additional live samples has not been pursued due to the expense of obtaining a parasite with a low prevalence $(0.7 \%)$ in a diminishing Diporeia spp. population in the Great Lakes.

\section{DISCUSSION}

Currently, the phylum Haplosporidia consists of 4 genera: Haplosporidium, Minchinia, Bonamia and Urosporidium. Urosporidium have no operculum but an internal lingua covering the orifice, whereas Haplosporidium and Minchinia have an operculum or lid covering an orifice at the anterior end (Perkins 1991). Bonamia spp. were not known to produce spores until B. perspora (Carnegie et al. 2006) was found with spores. The genus Haplosporidium was placed in phylum Haplosporidia based on DNA sequence data (Reece et al. 2004). There is considerable confusion about how to differentiate the genera 


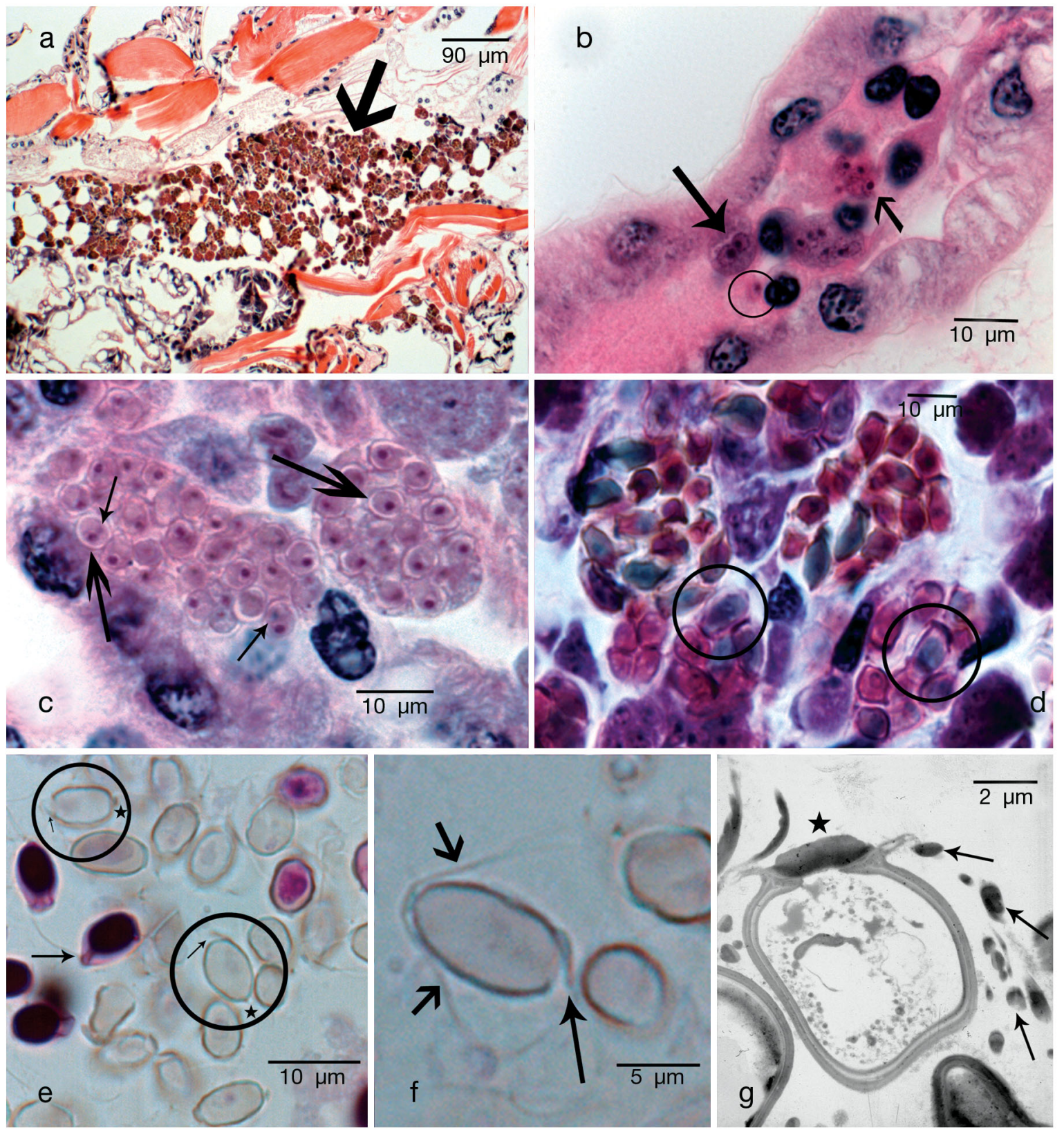

Fig. 2. Diporeia spp. Various morphologies and developmental stages of a haplosporidian in Diporeia spp. amphipods from Lakes Michigan and Huron. (a) Cross-section of infected Diporeia spp. with hemal spaces filled with haplosporidian sporocysts (large arrow). Heidenhain's hematoxylin and eosin (H\&E). (b) Hemal space in gill lumen of infected Diporeia spp. amphipod with haplosporidian parasite in various early stages of development. Sporonts containing numerous nuclei with small, dense endosomes (small arrow). Note granular and somewhat basophilic nature of sporont cytoplasm with no obvious separation between nuclei. Sporoblast with larger nuclei and acentric endosomes adjacent to the nuclear wall (large arrow). A small individual sporont with a single nucleus (encircled) is also apparent. Heidenhain's H\&E. (c) Haplosporidian sporoblasts with defined, dense and basophilic endosporoplasm. Note the translucent area between the endosporoplasm and spore wall (large arrows). The endosporoplasm of some sporoblasts contain a secondary basophilic body (small arrows). Heidenhain's H\&E. (d) Maturing haplosporidian sporoblasts; some are ellipsoidal with a limiting membrane apparent with dense basophilic structures in the apex of the elliptical developing spore (encircled). Heidenhain's H\&E. (e) Mature individual spores (encircled), some with a hinged operculum (small arrows) and a small projection $(\star)$ on the abopercular end of the spore. Note the bar-like projection on one spore (large arrow). Some spores had faint acid-fast bacteria (AFB)-positive staining internal structures or debris; mature spores were resistant to AFB stain. (f) Mature individual spores with a hinged operculum (long-tailed arrow) and thin, thread-like extensions or paired filaments (short-tailed arrows) emanating from the small projection on the abopercular end of spore. AFB stain. (g) Electron micrograph of developing spore with a lid over the operculum ( $\star$ ) and fairly large and extensive ornamentation (arrows) 
Haplosporidium and Minchinia (McGovern \& Burreson 1990, Burreson 2001). One approach to separating the genera is based on electron microscopy observation of extensions. Minchinia spp. have tails which are extensions of the epispore cytoplasm; Haplosporidium spp. have filaments or extensions of the spore wall that remain after the epispore cytoplasm is degraded (Ormieres 1980). In spite of this, regardless of whether extensions originate from the spore wall or in epispore cytoplasm, those species with extensions visible at the light microscope level were grouped in the genus Minchinia, and species without visible extensions were grouped in the genus Haplosporidium (Perkins 1990). Taxonomic placements are made more confusing since ornamentation on the type species of Haplosporidium, H. scolopli (Caullery \& Mesnil 1905), is considered to have extensions by some researchers (Sprague 1963, Perkins 1996) but to not have extensions by another researcher (Ormieres 1980).

Various species of freshwater snails from Michigan's Douglas Lake region were reported with the haplosporidian Haplosporidium pickfordi (Barrow 1961). The spores of this parasite were truncate, measuring $8.1 \times 4.3 \mu \mathrm{m}$ (Burreson 2001), slightly smaller than the original description of $8.9 \times 4.5 \mu \mathrm{m}$ (Barrow 1961). No ornamentation was elucidated at the optical microscopy level (Barrow 1961, Burreson 2001). SEM determined that spore ornamentation originated from the spore wall in 2 areas on the posterior end of the spore (Burreson 2001).

Some similarities exist between Haplosporidium pickfordi and the haplosporidian-like organism in Diporeia spp. Infected snails and amphipods were found in Lake Michigan and the range of these host species overlap. Both have an operculum and there is some indication the haplosporidian in Diporeia spp. has ornamentation originating from the posterior end of the spore, as does $H$. pickfordi. Although the reported width for $H$. pickfordi is smaller than that observed in the present study of the Diporeia spp. haplosporidian, this variation may be due to the type of fixation. Therefore, it is plausible that this parasite may be $H$. pickfordi. Additionally, certain stages of spore development in the haplosporidian found in Diporeia spp. amphipods are similar to those described in H. pickfordi (Barrow 1961) and H. lusitanicum (Azevedo 1984).

Haplosporidium parisi, H. pickfordi, and H. lusitanicum all have filaments coiled around the spore from bottom to the top in some stage of spore development (Ormieres 1980). Filaments on H. parisi (Ormieres 1980) and H. lusitanicum (Azevedo 1984) are attached to the spore wall at a single point and are formed as the spore wall is forming prior to lysis of the epispore cytoplasm (McGovern \& Burreson 1990). Without further analysis it is not possible to determine the number or arrangement of the filaments in the haplosporidian in Diporeia spp., or whether the AFB-positive stained thread-like and bar-like projections reported in the present study may be a filament developing as the spore wall is developing.

Based on histological morphology of the parasite found in Diporeia spp. amphipods from Michigan, this organism can be classified as a haplosporidian in the genus Haplosporidium based on the apparent spore wall-derived filaments. Specific identification of this haplosporidian awaits further investigation since adequate characterization of spore ornamentation and morphology requires both TEM and SEM. Molecular DNA sequence comparisons between the haplosporidian in Diporeia spp. and other haplosporidian parasites will elucidate its taxonomic relationship among the various species.

Acknowledgements. I thank S. Tyler for her exquisite TEM and histological processing of specimens. I also thank E. Burreson from Virginia Institute of Marine Science for expert consultation, A. Farley \& F. Kern, Cooperative Oxford Laboratory (both retired), for advice on histology, T. Nelapa of NOAA Great Lakes Environmental Research Laboratory for obtaining specimens, R. Overstreet, the co-author of the initial paper on prevalence of parasites in Diporeia spp., H. Kelsey for help with Fig. 1, and 2 anonymous manuscript reviewers.

\section{LITERATURE CITED}

Azevedo C (1984) Ultrastructure of the spore of Haplosporidium lusitanicum sp. n. (Haplosporida, Haplosporidiidae), parasite of a marine mollusc. J Parasitol 70:358-371

> Barrow JHJ (1961) Observations of a haplosporidian, Haplosporidium pickfordi sp. nov. in fresh water snails. Trans Am Microsc Soc 80:319-329

Barrow JHJ (1965) Observations on Minchinia pickfordae (Barrow 1961) found in snails of the Great Lakes region. Trans Am Microsc Soc 84:587-593

Burreson EM (2001) Spore ornamentation of Haplosporidium pickfordi Barrow, 1961 (Haplosporidia), a parasite of freshwater snails in Michigan, USA. J Eukaryot Microbiol 48:622-626

Carnegie RBE, Burreson EM, Hine PM, Stokes NA, Audemard C, Bishop MJ, Peterson CH (2006) Bonamia perspora n. sp. (Haplosporidia), a parasite of the oyster Ostreola equestris, is the first Bonamia species known to produce spores. J Eukaryot Microbiol 53:232-245

Caullery M, Mesnil F (1905) Recherches sur les Haplosporidies. Arch Zool Exp Gen 4:101-181

Conn HJ, Darrow MA, Emmel VM (1962) Staining procedures used by the Biological Stain Commission. Williams and Wilkins, Baltimore, MD

Farley CA (1965) Acid-fast staining of haplosporidian spores in relation to oyster pathology. J Invertebr Pathol 7: $144-147$

Howard DW, Smith CS (1983) Histologic techniques for marine bivalve mollusks. NOAA Tech Memo NMFS-F/ NEC-25

Howard DW, Lewis EJ, Keller BJ, Smith CS (2004) Histological techniques for marine bivalve mollusks and crustaceans. NOAA Tech Memo NOS-NCCOS 5 
Larsson JIR (1987) On Haplosporidium gammari, a parasite of the amphipod Rivulogammarus pulex, and its relationship with the phylum Ascetospora. J Invertebr Pathol 49: 159-169

Luna LG (1968) Manual of histologic staining methods of the Armed Forces Institute of Pathology. McGraw-Hill, New York

McGovern ER, Burreson EM (1990) Ultrastructure of Minchinia sp. spores from shipworms (Teredo spp.) in the western North Atlantic, with a discussion of taxonomy of the Haplosporidiidae. J Protozool 37:212-218

Messick GA, Overstreet RM, Nalepa TF, Tyler S (2004) Prevalence of parasites in amphipods Diporeia spp. from Lakes Michigan and Huron, USA. Dis Aquat Org 59:159-170

Ormieres R (1980) Haplosporidium parisi n. sp., Haplosporidie parasite de Serpula vermicularis L. étude ultrastructurale de la spore. Protistologica 16:467-474

Perkins FO (1990) Phylum Haplosporidia. In: Margulis JO, Corliss M, Melkonian Chapman DJ (eds) Handbook of Protoctista. Jones and Bartlett, Boston, MA, p 19-29

Perkins FO (1991) Sporozoa: Apicomplexa, Microsporidia, Haplosporidia, Paramyxea, Myxosporidia, and Actinosporidia. In: Harrison FW, Corliss JO (eds) Micro-

Editorial responsibility: Grant Stentiford, Weymouth, UK scopic anatomy of invertebrates. Wiley-Liss, New York, p 261-331

Perkins FO (1996) Phylum Haplosporidia Caullery and Mesnil, 1899. In: Lee JJ, Hutner SH, Bovee EC (eds) Illustrated guide to the Protozoa. Society of Protozoologists, Lawrence, KS

Perkins FO (2000) Phylum Haplosporidia Caullery \& Mesnil, 1899. In: Lee JJ, Leedale GF, Bradbury PC (eds) An illustrated guide to the Protozoa: organisms traditionally referred to as protozoa, or newly discovered groups, 2nd edn. Society of Protozoologists, Lawrence, KS, p 1432

Reece KS, Siddall ME, Stokes NA, Burreson EM (2004) Molecular phylogeny of the Haplosporidia based on two independent gene sequences. J Parasitol 90:1111-1122

Ryckeghem JV (1930) Les cnidosporidies et autres parasites de Gammarus pulex. Cellule 39:399-418

Sprague V (1963) Revision of genus Haplosporidium and restoration of genus Minchinia (Haplosporidia, Haplosporidiidae). J Protozool 10:263-266

Taylor RL (1966) Haplosporidium tumefacientis sp. n., the etiologic agent of disease of the California sea mussel, Mytilus californianus Conrad. J Invertebr Pathol 8: 109-121

Submitted: August 25, 2008; Accepted: November 10, 2008 Proofs received from author(s): January 30, 2009 